\title{
CONSTITUCIONALISMO POLÍTICO, PROCESSO DEMOCRÁTICO E O PAPEL DAS CORTES
}

\author{
POLITICAL CONSTITUTIONALISM, DEMOCRACY AND THE ROLE OF \\ COURTS
}

${ }^{1}$ Nikolai Olchanowski

\section{RESUMO}

A proposta de um constitucionalismo político por Richard Bellamy se ampara fundamentalmente na crítica ao constitucionalismo legal, isto é, na tradicional ideia em teoria constitucional de que a democracia deve ser balizada por princípios e condições inerentes à interação política. Bellamy, ao inserir conceitos como o rule of law, a previsão de direitos e o controle de constitucionalidade sob o crivo das circunstâncias da política, afirma que o constitucionalismo legal é, em verdade, hostil ao ideal democrático de autogoverno. Essa ideia pode ser lida sob as lentes da literatura produzida em ciência política, que também questiona a noção de rule of law como fundada num caráter distintivo das leis e das Cortes. $\mathrm{O}$ rule of law, nessa perspectiva, só é garantido mediante a adequada distribuição de incentivos aos indivíduos e, portanto, através da distribuição de poder político entre instituições. Bellamy, contudo, parece ignorar a hipótese de que leis e previsões constitucionais têm importante papel na solução de problemas de ação coletiva, papel este que, paradoxalmente, seria capaz de devolver importância ao tradicional constitucionalismo legal. A obra de Bellamy, no fundo, é relevante para mostrar que, sem fomento de participação política e adequada distribuição de poder de influência aos indivíduos, as previsões constitucionais e a atuação das Cortes podem ser inócuas ou mesmo prejudicar a construção de uma democracia.

Palavras-chave: Constitucionalismo político, Democracia, Richard bellamy, Rule of law

\footnotetext{
${ }^{1}$ Tribunal de Justiça do Estado do Paraná (TJPR), Paraná (Brasil). Mestrando em Direito pela Universidade Federal do Paraná (UFPR), Paraná (Brasil)
} 


\begin{abstract}
Richard Bellamys idea of a political constitutionalism is essentially based upon the critical analysis of legal constitutionalism, namely the traditional idea in constitutional theory that democracy should be restricted by the principles and conditions relating to political interaction. As Bellamy inserts concepts like the rule of law, rights prediction and judicial review under the scrutiny of the circumstances of politics, he states that legal constitutionalism is in fact hostile to the democratic ideal of self-government. This idea can be read through the lens of works in political science, which also put into question the idea that the rule of law is supported by a distinctive character of laws and courts. The rule of law, under this view, is only guaranteed through appropriate distribution of incentives to individuals and through the distribution of political power between institutions. Bellamy, however, seems to ignore the possibility that laws and constitutional provisions play an important role in solving collective action problems, a role that, surprisingly, would be able to give back importance to the traditional legal constitutionalism. Bellamys work is ultimately relevant to show that without fostering political participation and a fair distribution of influence power to individuals the constitutional provisions and the role of the courts can be worthless or even hostile to democracy building.
\end{abstract}

Keywords: Political constitutionalism, Democracy, Richard bellamy, Rule of law 


\section{Introdução}

Neste trabalho, realizo uma análise da proposta de Richard Bellamy (2007), que considero como uma radicalização de uma forte tendência em teoria constitucional, qual seja, a de questionar a legitimidade do papel das Cortes e a de pensar formas normativamente aprimoradas de democracia ${ }^{1}$.

Meu enfoque recai sobre os pontos de convergência entre o constitucionalismo político de Bellamy e a ciência política. Não abordo, portanto, as (relevantes) questões que poderiam ser discutidas desde a própria teoria constitucional e, principalmente, a filosofia política.

A estrutura do artigo é bastante simples. Primeiro, apresento rapidamente o que julgo de mais importante em Bellamy. Não se trata de uma resenha ou de um esforço de resumo da obra. Quero apenas fornecer ao leitor algumas proposições e ideias pertinentes à minha análise.

Depois, aproximo esses pontos a aportes teóricos da ciência política, com o intuito de demonstrar que Bellamy traz à teoria constitucional questões básicas na literatura que abordo, mas que, por serem geralmente negligenciadas no tratamento normativo e jurídico do constitucionalismo, apontam para direções interessantes.

Na última parte, apoiado na própria literatura que utilizo para ressaltar a convergência entre o constitucionalismo político e uma análise descritivamente válida da política, questiono se a proposta de Bellamy não ignora uma hipótese importante. Essa hipótese, se confirmada, seria capaz de devolver importância à tradicional estrutura constitucional.

Concluo ressaltando a importância de Bellamy menos como proposta normativa para o constitucionalismo do que como possibilidade de tornar a teoria constitucional e, por consequência, a ideia de democracia e direitos, mais sensíveis à literatura que apresento. Apesar de soar banal, a noção tem relevância, especialmente porque a própria teoria constitucional e a filosofia política começam a perceber a inevitabilidade de se pensar a fundo questões como desenho institucional e organização de poder.

\section{Bellamy e seu constitucionalismo político}

Como disse, nesse primeiro momento forneço alguns pontos que tomo como os mais relevantes no ambicioso Political Constitutionalism - A Republican Defense of the

\footnotetext{
${ }^{1}$ Para propostas bastante distintas, que partem dos problemas da legitimidade do constitucionalismo de das Cortes frente ao ideal democrático de autogoverno, ver: Ely (1980); Post, Siegel (2013); Kramer (2004); Gargarella (2014); Jaramillo (2014).
} 
Constitutionality of Democracy (BELLAMY, 2007). Ressalvo que descrevo esses pontos diretamente dessa obra, de forma que absolvo o leitor de referências inúteis ${ }^{2}$.

Bellamy divide seu livro em duas partes, que julga especialmente diferentes (p. 7; 145), mas cujos argumentos se repetem. Na primeira, discorre sobre o que chama de constitucionalismo legal, atrelado à tradicional teoria constitucional, a seu ver limitadora e prejudicial à democracia. Apresenta os argumentos utilizados pelos defensores dessa(s) teoria(s) e os refuta. $\mathrm{Na}$ segunda, fornece as bases do constitucionalismo político, calcado, fundamentalmente, no próprio processo democrático.

Duas expressões me parecem essenciais para compreender a teoria de Bellamy ${ }^{3}$. Me refiro a circunstâncias da justiça (p. 17-20) e a circunstâncias da política (p. 20-26), emprestadas, respectivamente, de David Hume (VANDERSCHRAAF 2006) e de Jeremy Waldron (1999).

Grosso modo, circunstâncias da justiça dizem respeito às pretensas pré-condições para a cooperação humana. Para usar os termos de Rawls, as circunstâncias da justiça derivam da necessidade de cooperação e do conflito de interesses daí decorrente (RAWLS, 1999, p. 109). O que Bellamy nega, em contraste com Rawls, é a possibilidade de um acordo pré-político acerca das condições para essa cooperação. Isso quer dizer que indivíduos têm divergências valorativas tão profundas que nenhum framework anterior é possível. Ou seja, se indivíduos querem garantir para si direitos, devem submetê-los ao debate. O que um acordo constitutivo pode visar, apenas, é fornecer um processo equitativo de tomada de decisão coletiva.

As circunstâncias da política, por sua vez, aprofundam o problema, já que se referem ao próprio dilema da decisão coletiva num ambiente de controvérsia valorativa. Indivíduos não discordam apenas porque são egoístas ou porque não possuem nenhuma empatia coletiva, mas porque formam preferências conflitantes - muitas delas derivadas de suas próprias reflexões sobre valores. Ainda, em sociedade, alguma decisão deve ser tomada (ELSTER, 1999, p. 149153), o que, longe de negar a possibilidade epistemológica de uma resposta correta ${ }^{4}$, cria limites práticos para uma busca por verdade.

\footnotetext{
${ }^{2}$ Os números em parêntese, quando sem outra referência, indicam as páginas em Bellamy (2007).

${ }^{3}$ Bellamy as debate no início de seu livro e as insere num tópico restrito a questionar o judicial review. Penso, no entanto, e isto ficará mais claro na segunda parte do meu texto, que tanto as circunstâncias da justiça quanto as circunstâncias da política põem à frente questões determinantes para toda a reflexão do autor - a ponto de a segunda parte da obra ser, de certo modo, de leitura prescindível. Quero, com isso, dizer que a proposição de Bellamy, apresentada da segunda parte de seu livro, é consequência direta das críticas ao constitucionalismo legal, apresentadas na primeira.

${ }^{4}$ Penso que a questão da objetividade (em sentido filosófico) é uma das maiores fraquezas da obra de Bellamy. Com efeito, se se pretende fundar uma teoria normativa com base na impossibilidade ou, ao menos, na imensa dificuldade prática de se obter uma resposta correta e justa, respostas mais elaboradas deveriam ser fornecidas (Bellamy 2007, p. 180-184). Dworkin, por exemplo, gasta muito tempo enfrentando justamente uma confusão
} 
Para Bellamy, sociedades pluralistas convivem com controvérsias valorativas e de preferências tão grandes que toda proposta coletiva gerará conflito. O dilema da política real é a improbabilidade de convergência de interesses (p. 163-171). Em verdade, nessa leitura, a profundidade dos conflitos dos conflitos entre indivíduos é particularmente problemática.

Como diria Shapiro (2011, p. 329-330), em sociedades tão diversificadas como a nossa, torna-se difícil imaginar mesmo uma convergência metodológica para esboçar uma de uma ideia de valores e práticas amplamente compartilhados, a exemplo do que propõe Dworkin (1986).

Ao apontar essas conclusões para conceitos muito familiares em teoria constitucional, o que Bellamy chama de constitucionalismo legal perde qualquer apelo de legitimidade. Assim, a revisão constitucional, a ideia de rule of $l a w^{5}$ e a própria estrutura das Constituições (ELSTER 2009, p. 129-139), com a previsão de direitos fundamentais, se apresentam como problemáticas.

A crítica fundamental em Bellamy diz respeito ao que ele chama de estratégias de despolitização (p. 147). Assim, o constitucionalismo legal retiraria certas questões para fora do âmbito político, elevando-as ao status de intocáveis e imutáveis. De um lado, construiria barreiras à política, estabelecendo valores, princípios e condições como anteriores e predeterminantes para a própria existência da sociedade. De outro, confiaria nas Cortes como limitadoras dos abusos da política e num caráter diferenciador do rule of law - com a previsão de direitos, mormente de caráter constitucional, entrincheirados (entrenched) num texto fundamental e inalterável.

O que o constitucionalismo legal faria, em suma, é balizar a democracia, limitá-la para que flua dentro de um certo quadro de princípios e condições (JARAMILLO, 2014), cuja presença e respeito se tornariam condições de possibilidade da mesma democracia.

Bellamy contesta radicalmente essa ideia. Na sua leitura, nada que diga respeito à vida em sociedade está alheio às circunstâncias da política. E, se nada pode ser estabelecido como um consenso pré-político ou como verdade objetiva, o estabelecimento de direitos inalienáveis e a confiança num órgão (Cortes) cujo papel é limitar o jogo democrático é o mesmo que apostar numa guardianship platônica (DAHL, 1998, p. 69-80) e desistir do ideal democrático de autogoverno.

presente em Bellamy, já que uma concepção interpretativa de direito nunca pretendeu fornecer uma ontologia da verdade. Ver: Dworkin (2011, p. 21-96; 1986, p. 87-112).

${ }^{5}$ Rule of law é usualmente traduzido como Estado de Direito. Penso que a tradução é, em geral, acertada. Sigo, contudo, o alerta de Troper (2003, p. 96), para quem a doutrina do Rechtstaat guarda diferenças importantes para o rule of law. Como trabalho com obras que pensam, essencialmente, a relação entre o rule of law, a democracia e constitucionalismo, uso o termo no original, a fim de evitar qualquer inconsistência. 
Essa ideia refuta mesmo propostas que mitigam a legitimidade das Cortes e limitam as pré-condições da política a regras procedimentais do jogo democrático - penso, fundamentalmente, em John Hart Ely (1980). Com efeito, em Bellamy, apenas a democracia pode garantir o autogoverno dos cidadãos. E o conceito de democracia, em sua leitura, não se diferencia da proteção de direitos e do rule of law, todos insertos nas circunstâncias da política e, portanto, dependentes do poder de influência dos indivíduos sobre as decisões coletivas (p. 141).

\section{Convergências}

A proposta de Bellamy busca expressamente se aproximar da literatura produzida em ciência política ${ }^{6}$. Quero apontar, agora, sob que aspectos essa pretensão foi cumprida.

Seguindo Elster (1989, p. 13-14), a ação dos indivíduos deve ser explicada em termos de suas intenções e oportunidades - o que podem ou não fazer. A afirmação é trivial, mas tem uma decorrência fundamental em política: instituições sociais, seu desenho e alteração são o resultado da ação de indivíduos. Isso não significa que se deva tratar a escolha social e a escolha individual de modo igual - a política não é uma simples escolha individual amplificada (ELSTER, 1999, p. 149) -, mas que a ação humana individual é a unidade de análise explicativa fundamental.

Logo, qualquer análise descritiva da política deve, antes de tudo, admitir que instituições são populadas por indivíduos (MARAVALL, PRZEWORSKI, 2003, p. 13).

Isso implica em reconhecer uma discrepância entre a abordagem usualmente adotada em teoria jurídica e constitucional (aquela que permearia o imaginário dos juristas MARAVALL, PRZEWORSKI, 2003, p. 1) e uma abordagem descritivamente válida. É que não há nenhum motivo para crer que indivíduos obedecem a normas em razão de um caráter distintivo da regra jurídica, mas sim porque derivam algum incentivo para assim se comportarem: “... a força da lei não é normativa - cidadãos e agentes políticos não obedecem à lei em razão de um dever de obediência. Em vez disso, agentes políticos obedecem à lei porque têm incentivos para tanto" (WEINGAST, 2003, p.109) ${ }^{7}$.

\footnotetext{
${ }^{6}$ No prefácio de seu livro, Bellamy afirma que sua tese seria controversa nas comunidades de teoria política e jurídica, mas muito mais aceita entre cientistas políticos.

${ }^{7}$ Tradução minha. No original: "The principle argument of this book is that the force of law is not normative citizens and political officials do not obey the law because of a duty to obey law. Instead, political officials obey the law because they have incentives to do so."
} 
Ou seja, mesmo presentes os oito princípios que Raz (1979, p. 214-219) atribui ao ideal do rule of $l a w^{8}$, a preservação e o cumprimento de regras jurídicas por grupos de interesse conflitantes se manteriam como fenômenos inexplicados.

Como mostra Przeworski (1991), democracias tendem a se manter quando perdedores têm incentivos suficientes para continuarem capitulando àquele sistema - e não iniciarem uma revolução, por exemplo. Mais, esses incentivos estão mais presentes em situação de afluência econômica (PRZEWORSKI, ALVAREZ, CHEIBUB, LIMONGI, 1996) e têm pouca ou nenhuma relação com uma cultura democrática ou de respeito a direitos (PRZEWORSKI/CHEIBUB/LIMONGI, 2003). Acima de algum nível de incentivos, perdedores simplesmente passam a aceitar os resultados de eleições, porque se revoltar seria mais custoso.

A ideia de rule of law, bem como a previsão de direitos dentro de um sistema legal, nessa perspectiva, passa a ser consequência do compartilhamento de um mesmo sistema legal por indivíduos que vislumbram incentivos para tanto. Nesse caso, a negação de Bellamy de que haja direitos completamente individuais (p. 29-35) ganha força, pois todo o arcabouço de proteção desses direitos dependerá da ação coletiva de respeitar as leis que os protegem:

\begin{abstract}
Se todos os interesses organizados renunciam à violência e recorrem ao mesmo corpo de lei e ao mesmo sistema legal para protegerem seus interesses e alcançarem seus objetivos, eles estão implicitamente relativizando seus interesses pessoais em bens coletivos, admitindo que sua perspectiva é parcial e que não merecem prevalecer em todos os casos (HOLMES, 2003, p. 51).
\end{abstract}

Ao afirmar que "a verdadeira proteção de direitos, do rule of law e mesmo da democracia vêm da democracia” (p. 141) ${ }^{10}$, Bellamy aproxima a teoria constitucional de uma leitura mais realista da política e da própria democracia.

\footnotetext{
${ }^{8}$ Raz fala, numa lista não exaustiva, em: (1) leis devem ser não retroativas, claras e abertas; (2) leis devem relativamente estáveis; (3) a produção normativa deve guiada por regras claras, estáveis, abertas e gerais; (4) o judiciário deve ser independente; (5) os princípios da justiça natural devem ser observados; (6) Cortes devem ter poder de revisão sobre a implementação dos outros princípios; (7) as Cortes devem ser de acesso fácil; e (8) a atuação das agências coercitivas não deve subverter o direito.

${ }^{9}$ Tradução minha. No original: "If all organized interests renounce violence and resort to the same body of law and the same legal system to protect their interests and carry out theirs purposes, they are implicitly relativizing their personal claims on collective assets, admitting that their perspective is partial and that they do not prevail in every case." Ver, no mesmo sentido: Maravall/Przeworski (2003, p. 4).

${ }^{10}$ Tradução minha. No original: "Throughout this critique of legal constitutionalism, I have maintained that the true protection of right, the rule of law and even democracy comes from democracy - the power of individuals citizens to claim and frame their rights and demand they be treated on equal terms with others".
} 
De fato, parece surgir uma ideia de democracia que se assemelha ao modelo inclusivista de Dahl (2005), no qual interessa muito mais o poder de barganha (ELSTER, 1989, p. 135-147) de cada indivíduo do que qualquer o conteúdo normativo das escolhas.

Com efeito, se o modelo de democracia dahlsiana pode ser chamado de minimalista (PRZEWORSKI, ALVAREZ, CHEIBUB, LIMONGI, 1996, p. 39) em termos de conteúdo, ele se torna exigente em termos de participação, igualdade de votos e, o que é particularmente importante, formação e controle da agenda política (DAHL, 1998, p. 35-43; 2005, p. 25-37).

Numa linguagem utilizada por Bellamy (p. 27), a qualidade dos outputs (resultados) do processo democrático só pode ser avaliada pelos inputs (inclusividadade).

Além disso, ao devolver a previsão de direitos (incluindo os chamados de fundamentais) e o trabalho desenvolvido pelas Cortes - não há razão para crer que juízes se comportam de maneira diversa dos demais indivíduos - ao âmbito da política, Bellamy corretamente atesta que o Direito e as leis não podem ser separados do jogo político (MARAVALL/PRZEWORSKI, 2003, p. 15): “as Cortes integram o sistema político e, de modo mais geral, a cultura de governo. Seria não apenas impossível, como também inapropriado buscar isolá-las inteiramente dessas influências" (p. 39) ${ }^{11}$.

Tal perspectiva, por óbvio, é radicalmente oposta a qualquer tese que procure separar a posição de julgamento de juízes daquele de outros atores políticos, manifestada de forma mais coerente e sofisticada no Direito como integridade dwokiniano, para o qual "juízes estão numa posição muito diferente de legisladores" (DWORKIN, 1986, p. 244) ${ }^{12}$.

Concorde-se ou não com essa constatação em termos normativos, o grande mérito dessa perspectiva é remeter importância (normativa) ao processo de decisão coletiva - só daí podem resultar direitos fundamentais, por exemplo -, que como visto, depende de preferências individuais. O surpreendente é que Bellamy (p. 191-195) põe à frente uma leitura do processo democrático que escapa da visão estereotipada dos juristas, isto é, algo como um winner takes all, em que minorias e derrotados inevitavelmente teriam seus direitos e interesses prejudicados.

Em verdade, em democracias funcionantes, a formação de maiorias é dependente de trade-offs entre os mais diversos grupos de interesses e alterada profundamente pelo desenho institucional (LIJPHART 2012; TSEBELIS 2002). Construir maiorias exige fazer e propor compromissos, o que torna qualquer decisão um processo relativamente complexo.

\footnotetext{
${ }^{11}$ Tradução minha. No original: "For a start, courts form part of the political system and the more general culture of the polity. It would be not only impossible but also inappropriate to seek to isolate them from such influences entirely".

${ }^{12}$ Tradução minha. No original: "Law as integrity assumes, however, that judges are in a very different position from legislators".
} 
O papel das Cortes, ainda, nada mais é do que o de um ator político, capaz ou não de alterar as decisões da maioria legislativa, a depender do desenho institucional e da formação de preferências dos demais atores (TSEBELIS, 2002, p. 222-247; ROBL FILHO; TOMIO, 2013).

Nesse caso, torna-se mesmo difícil justificar que um papel especial e fora da política seja ofertado ao Judiciário. Outrossim, parece indiscutível que as circunstâncias da política permeiam (e, inclusive, aqui se mostrem mais presentes) a formação de Constituições abarcando, é claro, a previsão de direitos e a organização do Estado.

Bellamy, portanto, tem toda razão ao afirmar que a base da democracia está na distribuição equânime de poder decisório (p. 230). O rule of law, como garantia de ação previsível e equitativa perante os cidadãos (HOLMES 2003), surge quando nenhum grupo de interesse é poderoso o suficiente para dominar os demais e a lei passa a refletir múltiplos interesses (MARAVALL/PRZEWORSKI, 2003, p. 4).

\section{Auto-restrição, pontos de foco e o interesse dos juízes}

Constituições podem ser pensadas como mecanismo de auto-restrição, desde que tomados os devidos cuidados para não se confundir uma consequência por uma explicação (ELSTER 2009: 121-128). Isto é, auto-restrição, em respeito às Constituições, se limita aos casos em que uma maioria, no momento constituinte, decide restringir seus próprios poderes parlamentares, mesmo esperando manter-se futuramente como maioria. Essa estratégia, além disso, deve ser intencional e formulada em razão de benefícios esperados - essencial, nos termos de Elster (ROBL FILHO/TOMIO, 2013, p. 98-99).

Como mostra Lijphart (2012, p. 204-225), o controle de constitucionalidade não é onipresente em democracias, além de se manifestar sob diferentes desenhos e importâncias. A mesma afirmação é válida para o processo de alteração (emenda) de constituições, ou mesmo para a existência de um bill of rights. São mecanismos, portanto, surgidos como opções de maiorias constituintes.

Seguindo o próprio caminho deixado por Bellamy e que procurei expor nas partes anteriores deste trabalho, a opção por um constitucionalismo legal só pode ser resultado de um processo de formação de maiorias (já que tampouco o momento constituinte estava alheio às circunstâncias da política).

Consequentemente, a opção pela estrutura constitucional que contenha previsões de direitos altamente estáveis e que seja controlada por um órgão independente só pode ser 
resultado de dois raciocínios: a) ou maiorias constituintes se auto-restringem e esperam melhores resultados se tiverem menos poder; ou b) maiorias constituintes restringem aos outros.

Forçoso lembrar, portanto, que "o indivíduo que quer se auto-restringir pode confiar sua vontade a instituições ou forças externas, além de seu controle, que o impeçam de mudar de opinião. Mas não há nada externo à sociedade..." (ELSTER, 2009, p. 127). E o mesmo raciocínio vale para aquele indivíduo que pretende restringir aos outros.

Nesse caso, se o processo democrático, segundo Bellamy, oferece "incentivos para formação de compromissos que são atentos aos diversos interesses de uma ampla gama de grupos na sociedade” (p. 259) ${ }^{13}$, é difícil explicar por que grupos de interesse tão variados comporiam uma maioria constituinte a qual optasse por sistema que tendencialmente lhes oprimisse e dominasse (p. 147-154). A não ser estejamos diante de um caso de coletivo e hiperdimensionado de falha de racionalidade (ELSTER, 1999, p. 11-39; 1989, p. 30-41), esses grupos de interesse percebem incentivos importantes em respeito ao constitucionalismo legal.

Ora, se o rule of law só se sustenta porque indivíduos se sentem motivados a obedecer à lei, tal regra se estende às previsões constitucionais, bem como às decisões emanadas pelas Cortes.

Uma hipótese que me parece interessante para responder a esse paradoxo é a de que leis servem como pontos de foco (focal points), na medida em que solucionam (ou atenuam) problemas de coordenação de indivíduos (MARAVALL/PRZEWORSKI, 2003, p. 5) ${ }^{14}$. Tomando as Constituições e o rule of law como instituições sociais (ELSTER 1989, p.147158), é preciso reconhecer que o backup do poder coercitivo do Estado facilita a criação de expectativas pelos cidadãos - inclusive e principalmente, em relação às condutas do próprio Estado:

Para que o rule of law surja, cidadãos devem de algum modo solucionar seu problema de coordenação, a fim de que possam agir em conjunto contra uma potencial transgressão. Suas divergências fundamentais acerca do Estado tornam essa coordenação problemática. Solucionar esse dilema de coordenação requer formar um mecanismo de coordenação - frequentemente uma constituição, mas geralmente um pacto. A essência desse novo mecanismo é que ele coordena cidadãos em sua reação frente ao Estado. Assim, as constituições e os pactos como mecanismos de coordenação criam novos procedimentos para a tomada de decisão estatal e direitos dos cidadãos. Essas especificações definem o significado de uma transgressão, ajudando, deste modo, os cidadãos a se coordenarem: um governo que viola esses

\footnotetext{
${ }^{13}$ Tradução minha. No original: "Rather than crude mechanisms whereby majorities ride roughshod over rights of minorities, democratic practices offer incentives for building compromises that are attentive to the diverse concerns of a broad range of groups in society”. ${ }^{14}$ Sobre o problema da coordenação de indivíduos ou da ação coletiva, conferir: Elster (1989, p. 124-134). procedimentos ou direitos está, por definição, transgredindo (WEINGAST, 2003, p. 111) ${ }^{15}$.
} 
Nesse sentido, o rule of law, em termos descritivos, é capaz de se aproximar de seu ideal normativo.

Para tomar um autor que pensa particularmente a ideia de valor do rule of law (RAZ, 2009, p. 220) - e referido como paradigma do imaginário dos juristas sobre a questão (MARAVALL/PRZEWORSKI, 2003, p. 1-3) -, leis seriam capazes de estabilizar relações sociais potencialmente erráticas e imprevisíveis e, por meio de estratégias de auto-restrição, criariam a possibilidade de planificação das condutas humanas.

Contudo, como visto, tanto a eleição de uma estratégia determinada estratégia de autorestrição, como o valor que exsurgiria da possibilidade de planificação de condutas (através de regras estáveis e previsíveis) só podem ser explicados, em última análise, através da conduta de indivíduos que povoam instituições sociais.

É dizer, em determinadas condições e sob determinados incentivos, os quais podem ser alterados por instituições e normas sociais (ELSTER, 1989), vislumbram-se como vantajosas as estratégias de se auto-restringir, em prol da possibilidade de planificação de condutas e da estabilização de relações sociais.

A existência de uma Constituição escrita e a previsão de direitos, portanto, podem muito bem não ser estratégias de despolitização, como quer Bellamy (p. 147), mas representarem um importante mecanismo de coordenação dos cidadãos - não porque se neguem divergências de preferências entre os indivíduos, mas justamente porque diante dessas divergências a ação coletiva é tão problemática.

Cortes também são instituições sociais e seu papel também pode ser lido como o de solucionar problemas de ação coletiva (ELSTER 1989, p. 153). Mas há uma distância grande entre estabelecer Constituições escritas e afirmar (como faz a teoria constitucional dominante), que "submeter a performance de funções públicas ao escrutínio de juízes independentes se torna um efetivo e essencial controle no exercício do poder político" (GUARNIERI, 2003, p.

\footnotetext{
15 Tradução minha. No original: "For the rule of law to emerge, citizens must somehow solve their coordination problem so that they can act in concert against potential transgression. Their fundamental differences about the state make this coordination problematic. Solving this coordination dilemma requires constructing a coordination device - often a constitution but generally a pact. The essence of the new device is that it coordinates citizens in their reaction to the state. Thus, the constitutions and pacts qua coordination devices typically create new procedures for governmental decision making and the rights of citizens. These specifications define the meaning of a transgression, thus helping citizens to coordinate: a government that violates these procedures or right is, by definition, transgressing”.
} 
$223)^{16}$ ou, mais radicalmente, que juízes decidem de forma diversa de políticos (DWORKIN, 1986).

Contudo, desde a abordagem da interação entre atores políticos insertos em desenhos institucionais (ROBL FILHO; TOMIO, 2013, p. 98), a proteção de direitos e as decisões por princípios podem ser pensados como resultado dos próprios interesses dos juízes. Como nota Troper (2003, p. 104-107), Cortes têm sobre si constrangimentos intrínsecos - mesmo que se chame aquela instituição de suprema. Tribunais são populados por indivíduos que possuem o peculiar interesse em parecer desinteressados - atores institucionais devem fornecer razões que sejam vistas como consistentes com suas prerrogativas institucionais (MARAVALL; PRZEWORSKI, 2003, p. 7).

Nesse caso, as Cortes não têm um diferencial em relação às outras instituições que não aquele de que são institucionalmente constrangidas a decidirem estável e equitativamente (como requer o rule of law).

A força desse constrangimento depende muito mais do desenho institucional e, consequentemente, do controle que se exerce sobre esse órgão do que de qualquer papel normativo que se dê aos juízes (guardiões da Constituição, da democracia etc.). Contudo, uma implicação surpreendente é que a relevância da teoria constitucional e jurídica, sob o viés normativo-principiológico, reaparece se pensarmos no requerimento dessa abordagem de decisões coerentes, previsíveis e condizentes com o papel institucional que se atribuí à Corte. É dizer, ao melhor definir o significado de transgressões (WEINGAST, 2003), uma doutrina jurídica sofisticada tenderia a constranger juízes a decidirem de forma mais condizente com o que deles se espera.

A hipótese que proponho é relativamente simples: (a) Cortes têm sobre si o constrangimento institucional de decidirem conforme o rule of law; (b) leis servem como pontos de foco para minimizarem os problemas de ação coletiva; e (c) logo, ao se esperar que as Cortes decidam conforme princípios de justiça e equidade e segundo um devido processo (DWORKIN, 1986, p. 243), o papel das Cortes perante o problema da ação coletiva é acentuado.

De forma geral, penso que a proposta de Bellamy é relevante para, em última análise, chamar a atenção para a necessidade de se pensar a atuação das Cortes como eminentemente política. E isso não significa desvalorizá-las ou chamar os juízes de egoístas e insensíveis, mas simplesmente constatar que instituições como as Cortes não têm qualquer origem

\footnotetext{
${ }^{16}$ Tradução minha. No original: "Therefore, submitting the performance of public functions to the scrutiny of independent judges becomes an effective and essential check on the exercise of political power, ensures the supremacy of the law, and guarantees citizens' rights".
} 
transcendental. São pensadas e criadas como mecanismos com objetivos determinados por maiorias constituintes e, justamente por isso, devem responsividade aos objetivos que a elas se atribuiu.

Daí que teorias que afirmem a importância das Constituições e das Cortes como aliados para a construção da democracia, e, ao mesmo tempo, guardem consciência de que não se pode apostar nesses instrumentos sem fomentar a igualdade política entre os cidadãos, inclusive na esfera material (POST/SIEGEL, 2013; GARGARELLA, 2014), me parecem particularmente interessantes.

\section{Conclusão}

Não tenho especial simpatia pela proposta de Bellamy como teoria normativa para o constitucionalismo - penso que seu republicanismo de fundo (p. 145-146) tem poucas respostas para algumas objeções importantes desde a filosofia política ${ }^{17}$.

Vejo, entretanto, sua obra como relevante para chamar a atenção sobre a possibilidade de se pensar teoria constitucional e da democracia sem perder de vista o que foi produzido como abordagem descritiva sobre o assunto.

Em verdade, pensar normativamente a relação entre constitucionalismo e democracia tem levado muitos teóricos a ressaltar a importância da política e, o que é menos comum, a relação entre atores políticos (POST/SIEGEL 2013; TUSHNET 2008). Como tentei mostrar, de toda sorte, isso não significa retirar importância de uma abordagem mais usual a juristas.

Isso dito, o mais fundamental em Bellamy, me parece, é apontar para o fato de que, não só o desenho institucional importa para o funcionamento de democracias, como a previsão de direitos e sua garantia por Cortes podem ser estratégias vazias e mesmo deletérias se desacompanhadas de participação efetiva no processo decisório (p. 230).

Em suma, Cortes, previsões constitucionais altamente estáveis e mecanismos afins podem se configurar como instrumentos valiosos de aprimoramento de democracias, desde que (e somente assim) garantida e incentivada a igualdade política entre seus participantes e, consequentemente, a inexistência de instituições não controladas. A pretensão de criar de uma democracia mais suave e gentil (LIJPHART, 2012, p. 274-303), portanto, pode ganhar muito com provisões constitucionais bem elaboradas, mas é principalmente dependente do controle (democrático) de todas as instituições, incluindo, evidentemente, as Cortes:

\footnotetext{
${ }^{17}$ Sobre o assunto, ver: Gargarella (1999, p. 161-190)
} 
Em particular, se o governo como um todo deve ser limitado, não deve haver um "fiscal não fiscalizado", agências que poderiam fiscalizar outras sem estarem sujeitos a serem por elas fiscalizadas. Se as Cortes podem ordenar outros ramos do governo e esses ramos não podem controlar os tribunais, o poder do Judiciário não é fiscalizado. A moderação emerge, nesta concepção, somente se cada ação de qualquer ramo requerer a cooperação de algum outro ramo para ser eficaz (MARAVALL; PRZEWORSKI, 2003, p. 11) ${ }^{18}$.

Como concluiu recentemente Gargarella (2014), talvez se tenha esquecido de que Constituições só logram garantir direitos mediante distribuição de poder político e de que somente uma sociedade efetivamente inclusiva, em que a deliberação pública e coletiva entre os diversos atores políticos seja constante, pode ser denominada democrática.

\footnotetext{
${ }^{18}$ Tradução minha. No original: "In particular, if the government as a whole is to be limited, there must be no 'unchecked checker', agencies that can check others without being subject to checks by them. If the courts can dictate to the other branches of the government, and these branches cannot control the courts, the power of the judiciary is unchecked. Moderation emerges in this conception only if every action of any branch requires cooperation of some other branch to be effective".
} 


\section{Referências}

BELlAMY, Richard. Political Constitutionalism. A Republican Defense of the Constitutionality of Democracy. Cambridge: Cambridge University Press, 2007.

DAHL, Robert A. Poliarquia: participação e oposição. São Paulo: Editora da Universidade de São Paulo, 2005.

. On democracy. New Haven: Yale University Press, 1998.

DWORKIN, Ronald. Justice for hedgehogs. Cambridge: Harvard University Press, 2011.

. Law's Empire. Cambridge: Harvard University Press, 1986.

ELY, John Hart. Democracy and Distrust: A Theory of Judicial Review. Cambridge: Harvard University Press, 1980.

ELSTER, Jon. Ulisses liberto: estudos sobre racionalidade, pré-compromissos e restrições. São Paulo: Editora UNESP, 2009. . Nuts and Bolts for the Social Sciences. Cambridge: Cambridge University Press, 1989.

GARGARElla, Roberto. La Sala De Maquinas De La Constitución. Dos Siglos de Constitucionalismo en América Latina (1810 - 2010). Buenos Aires: Capital Intelectual, 2014.

Las teorías de la justicia después de Rawls. Un breve manual de filosofía política. Barcelona: Paidós, 1999.

GUARNIERI, Carlo. Courts as an Instrument of Horizontal Accountability: The Case of Latin Europe. In: MARAVALL, José María; PRZEWORSKI, Adam (eds). Democracy and the rule of law. Cambridge: Cambridge University Press, 2003. p. 223-241.

. Juicios Salomónicos. Las limitaciones de la racionalidad como principio de decisión. Barcelona: Editorial Gedisa, 1999. 
HOLMES, Stephen. Lineages of the Rule of Law. In: MARAVALL, José María; PRZEWORSKI, Adam (eds). Democracy and the rule of law. Cambridge: Cambridge University Press, 2003. p. 19-61.

JARAMILLO, Leonardo García (Org.). Nuevas perspectivas sobre la relación/tensión entre la democracia y el constitucionalismo. Lima: Grijley, 2014.

KRAMER, Larry. The people themselves: popular constitutionalism and judicial review. New York: Oxford University Press, 2004.

LIJPHART, Arend. Patterns of democracy: government forms and performances in thirty-six countries. 2 ed. New Haven: Yale University Press, 2012.

MARAVALL, José María; PRZEWORSKI, Adam. Introduction. In: MARAVALL, José María; PRZEWORSKI, Adam (eds). Democracy and the rule of law. Cambridge: Cambridge University Press, 2003. p. 1-16.

POST, Robert; SIEGEL, Reva. Constitucionalismo democrático. Por una reconciliación entre Constitución y Pueblo. Buenos Aires: Siglo veintiuno, 2013.

PRZEWORSKI, Adam. Democracy and the Market. Cambridge: Cambridge University Press, 1991.

PRZEWORSKI, Adam; ALVAREZ, Michael; CHEIBUB, José Antonio; LIMONGI, Fernando. What Makes Democracies Endure? Journal of Democracy. Vol. 7. No. 1 (1996) p. 39-55.

PRZEWORSKI, Adam; CHEIBUB, José Antonio; LIMONGI, Fernando. Democracia e cultura: uma visão não culturalista. Lua Nova. No. 58 (2003).

RAWLS, John. A theory of justice. Revised edition. Cambridge: Harvard University Press, 1999.

RAZ, Joseph. The authority of Law. 2 ed. Oxford: Oxford University Press, 2009. 
ROBL FILHO, Ilton Norberto; TOMIO, Fabricio Ricardo de Limas. Empirical legal Research: teoria e metodologia para a abordagem do processo decisório de controle de constitucionalidade no STF. In: SIQUEIRA, Gustavo Silveira; VESTENA, Carolina Alves (coord). Direito e experiências jurídicas: debates práticos. V1. 2. Belo Horizonte: Arraes Editores, 2013. p. 96117.

SHAPIRO, Scott J. Legality. Cambridge: Harvard University Press, 2011.

TROPER, Michel. Obedience and Obligation in the Rechtstaat. In: MARAVALL, José María; PRZEWORSKI, Adam (eds). Democracy and the rule of law. Cambridge: Cambridge University Press, 2003. p. 94-108.

TSEBELIS, George. Veto Players. How political institutions work. Princeton: Princeton University Press, 2002.

TUSHNET, Mark. I Dissent: Great Opposing Opinions in Landmark Supreme Court Cases. Boston: Beacon, 2008.

VANDERSCHRAAF, Peter. The circumstances of justice. Politics, Philosophy \& Economics. Vol. 5. No. 3 (October 2006). p. 321-351.

WEINGAST, Barry R. A postscript to "Political Foundations of Democracy and the Rule of Law. In: MARAVALL, José María; PRZEWORSKI, Adam (eds). Democracy and the rule of law. Cambridge: Cambridge University Press, 2003. p. 109-113.

WALDRON, Jeremy. Law and Disagreement. Oxford: Oxford University Press, 1999. 